\title{
Transient decrease in number of motor units after immobilisation in man
}

\author{
A NDERS FUGLSANG-FREDERIKSEN AND ULLA SCHEEL \\ From the Laboratory of Clinical Neurophysiology, Rigshospital, University of Copenhagen, Denmark
}

S UMMARY On the day after the removal of a long leg cast, when the patient could just bend his knee, the electrical activity in the disused quadriceps muscle showed changes that indicated a reduction in the number of motor units. At 10 to $75 \%$ of maximum force the number of turns and the mean amplitude of the needle-recorded EMG were reduced in the disused muscle. Eight days later, when half the initial loss of force had been regained, the electrical activity was normal. The electrical activity produced during a constant force of $5 \mathrm{~kg}$ did not differ in the disused and in the contralateral muscle. From the findings in normal subjects it was deduced that the compensatory increase in turns in the EMG pattern to be expected from the decrease in cross-sectional area of the muscle fibres was within the error of the method. The transient decrease in the number of turns and in mean amplitude of the EMG of the disused muscle are an indication of the plasticity of the motor system.

Inactivity of a muscle results in a diminished force usually attributed to atrophy of the muscle fibres (Adams, 1975). Our study was initiated by the observation that the force of the atrophic quadriceps muscle increased from $40 \%$ to $80 \%$ of the force of the contralateral muscle within one week after immobilisation. This rate of increase did not seem compatible with the time required for recovery of the cross-sectional area of the muscle fibres. To distinguish between a diminished cross-sectional area of muscle fibres and a reduced number of activated motor units, we analysed the pattern of electrical activity in the muscles of eight patients during recovery after immobilisation. The difference in the EMG pattern obtained during a force adjusted relative to the maximum force and during a standard force allows this differentiation to be made (Fuglsang-Frederiksen and Månsson, 1975; Fuglsang-Frederiksen et al., 1977).

\section{Patients and method}

Eight patients, six men aged $20-32$ years and two women aged 20 and 42 years, were investigated. The right or the left leg was immobilised in a long

\footnotetext{
Address for reprint requests: Dr Anders Fuglsang-Frederiksen, Laboratory of Clinical Neurophysiology, Rigshospitalet, 2100 Copenhagen $\varnothing$, Denmark.

Accepted 22 May 1978
}

plaster cast for 27 to 43 days after an acute lesion of the medial collateral ligament of the knee. In six patients the ligament was sutured (Table). The force and electrical activity were measured after removal of the cast when the patient could just bend his knee to $90^{\circ}$ (six patients) or to $45^{\circ}$ (two patients). This was denoted as day 0 . Eight days (day 8) and 30 days (day 30) later the study was repeated. The contralateral normal leg was examined on day 0 and on day 30 . The leg was trained three times weekly from day 8 or 10 , in one patient from day 20. The effect of different types of training will be reported elsewhere (Halkjær-Christensen and Ingemann-Hansen, in preparation).

MEASUREMENT OF FORCE

The patients were examined in a sitting position with the knee bent to an angle of $90^{\circ}$ or $45^{\circ}$. The isometric force of the knee extensors was measured just above the ankle joint by means of a nonelastic strap connected to a strain gauge. The maximum force $\left(\mathbf{P}_{0}\right)$ was recorded on an inkwriter before the electrodes were inserted, and after they had been removed. The electrical activity of the appropriate muscle was recorded at 10 and $30 \%$ of $\mathrm{P}_{0}$ and at a standard force of $5 \mathrm{~kg}$. To maintain a constant force the subjects kept the pointer of a galvanometer, connected to the output of the strain gauge, at a given deflection. 
Table Time of immobilisation and decrease in force in the quadriceps muscle in eight patients with a lesion of the medial ligament of the knee joint

\begin{tabular}{|c|c|c|c|c|c|c|c|c|c|}
\hline \multirow[t]{2}{*}{ Number } & \multirow{2}{*}{$\begin{array}{l}\text { Age } \\
(y r)\end{array}$} & \multirow[t]{2}{*}{$\operatorname{Sex}$} & \multirow{2}{*}{$\begin{array}{l}\text { Suture of } \\
\text { ligament }\end{array}$} & \multirow{2}{*}{$\begin{array}{l}\text { Days in } \\
\text { cast }\end{array}$} & \multirow{2}{*}{$\begin{array}{l}\text { Days after } \\
\text { removal of } \\
\text { cast* }\end{array}$} & \multirow{2}{*}{$\begin{array}{l}\text { Angle at } \\
\text { Day } 0\end{array}$} & \multicolumn{3}{|c|}{ Percentage decrease in maximum force $\left(P_{0}\right) \dagger$} \\
\hline & & & & & & & Day 0 & Day 8 & Day 30 \\
\hline 1 & 32 & $\mathbf{M}$ & - & 31 & 0 & $90^{\circ}$ & 59 & 31 & 0 \\
\hline 2 & 27 & $\mathbf{M}$ & + & 39 & 0 & $45^{\circ}$ & 38 & 16 & 3 \\
\hline 3 & 23 & $\mathbf{M}$ & + & 39 & 0 & $45^{\circ}$ & 60 & 29 & 5 \\
\hline 4 & 22 & $\mathbf{M}$ & - & 28 & 1 & $90^{\circ}$ & 55 & 23 & 12 \\
\hline 5 & 28 & $\mathbf{M}$ & $\therefore$ & 27 & 7 & $90^{\circ}$ & 65 & - & 5 \\
\hline 6 & 20 & $\mathbf{M}$ & - & 37 & 11 & $90^{\circ}$ & 77 & - & - \\
\hline 7 & 20 & $\mathrm{~F}$ & - & 43 & 28 & $90^{\circ}$ & 71 & - & 21 \\
\hline 8 & 42 & $\mathrm{~F}$ & + & 37 & 57 & $90^{\circ}$ & 42 & - & - \\
\hline
\end{tabular}

*Day 0 the day when the patient just could bend his knee to $90^{\circ}$ or $45^{\circ}$.

tThe decrease in force as a percentage of the force of the contralateral quadriceps muscle.

QUANTITATION OF PATTERN OF ELECTRICAL ACTIVITY Criteria (Willison, 1964) The number of spikes per $5 \mathrm{~s}$ (turns/5s) with a threshold of voltage shift of $100 \mu \mathrm{V}$; the amplitude of the pattern, given as the amplitude between the spikes. The number of turns and the amplitudes were counted automatically (Medelec APA6, Fitch, 1967; FuglsangFrederiksen and Månsson, 1975).

Position of electrodes and number of sites examined Concentric needle electrodes (DISA 13K32) were placed in four standardised positions in the medial, lateral, and intermedius vastus muscles. In all, 12 sites were examined. The rectus femoris muscle was not examined because it was often not activated at a force less than $30 \%$ of maximum (Thage, 1974).

Number of turns during a gradual increase in force In patients 1 and 4 , the number of turns in the EMG tracing was counted in the disused and in the contralateral muscle in successive intervals of 100 $\mathrm{ms}$ when the force was increased up to 50 or $75 \%$ of $P_{0}$. The force was recorded on an inkwriter to ascertain a linear increase in force within 10 seconds.

INDIVIDUAL MOTOR UNIT POTENTIALS AND PATTERN OF RECRUITMENT

On day 0,22 to 43 individual motor unit potentials were sampled during weak effort of the disused and the normal medial vastus muscle. The average total duration, the peak-to-peak amplitude, and the incidence of polyphasic potentials were determined (Buchthal, 1957).

The pattern of recruitment was recorded during full effort, and the amplitude of the envelope curve of the EMG trace was measured.

\section{Results}

On day 0 the maximum isometric force $\left(P_{0}\right)$ of the quadriceps muscle was diminished by 40 to $80 \%$ of that in the contralateral muscle (Fig. 1).

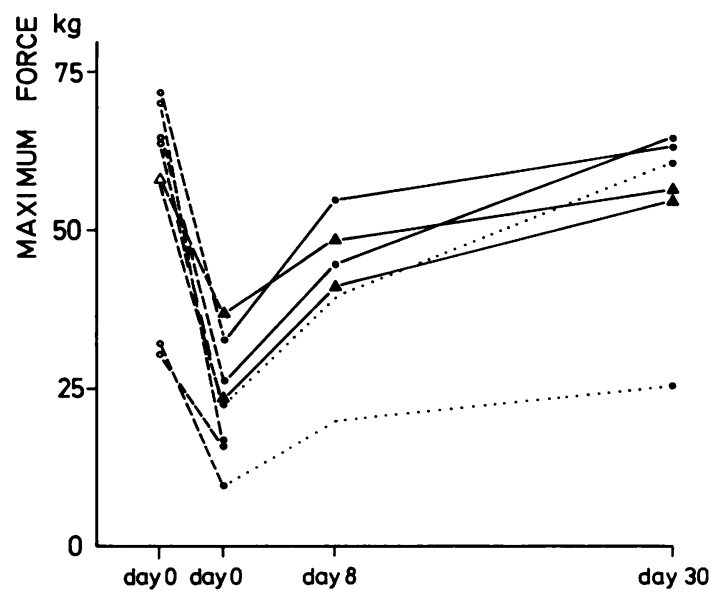

Fig. 1 Maximum force in the normal and in the disused quadriceps muscle. The dashed lines connect measurements in the normal $(O \triangle)$ and in the disused quadriceps muscle ( $\bullet$ ). The dotted lines connect findings at day 0 and day 30 in patients in whom no measurements were obtained at day 8. The abscissa denotes days after the patient could just bend his knee to $90^{\circ}$ ( $\bullet$ ) or to $45^{\circ}$ ( (A).

ELECTRICAL ACTIVITY IN THE DISUSED AND IN THE CONTRAlateral MUSCle at $10 \%$ and $30 \%$ of $\mathbf{P}_{0}$ The number of turns $/ 5 \mathrm{~s}$ in the disused muscle was diminished by 20 to $60 \%$ at $10 \%$ of $P_{0}$ compared with the number of turns $/ 5 \mathrm{~s}$ in the contralateral muscle at $10 \%$ of $P_{0}(P \leqslant 0.01$, Fig. 2). At $30 \%$ of $\mathbf{P}_{0}$, the decrease in the number of turns in the disused muscle was 25 to $50 \%$ ( $P \leqslant 0.05$, Fig. 3). The mean amplitude in recording from the disused muscle was diminished by 15 to $45 \%$ at $10 \%$ of $P_{0}$ compared with the mean amplitude at $10 \%$ of $\mathbf{P}_{0}$ in the contralateral muscle ( $\mathrm{P} \leqslant 0.01$, Fig. 2). At $30 \%$ of $P_{0}$ the diminution was 30 to $60 \%$ in the disused muscle ( $P \leqslant 0.05$, Fig. 3). The diminution in turns and in mean amplitude of the recording was the same in the different portions of the quadriceps muscle. 
10 PER CENT OF MAXIMUM FORCE
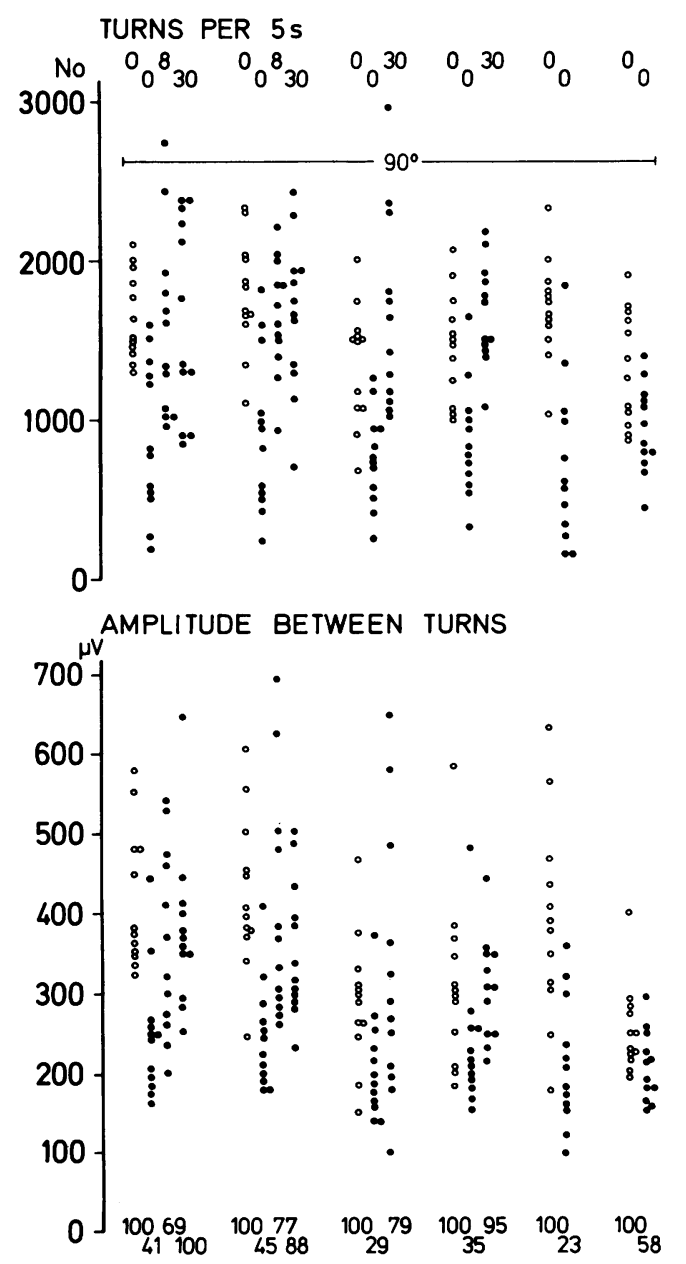

The number of turns per $100 \mathrm{~ms}$ increased linearly with increasing relative force up to 50 to $75 \%$ of $P_{0}$ in the disused muscle (Fig. 4). In normal muscle the number of turns increased more exponentially, approaching maximum at 30 to $50 \%$ of $P_{0}$ (Fig. 4). In the disused muscle the number of turns at 50 to $75 \%$ of $P_{0}$ was equal to that in the normal muscle at 10 to $30 \%$ of $P_{0}$.

On day 8 (four patients) the diminution in force was half that on day 0 -that is, 15 to $30 \%$ of $P_{0}$ in the contralateral muscle (Fig. 1). At $10 \%$ of $\mathbf{P}_{0}$ in the disused muscle the number of turns had recovered fully (Fig. 2). The mean amplitude between turns had also recovered fully.

On day 30 (six patients) the number of turns and

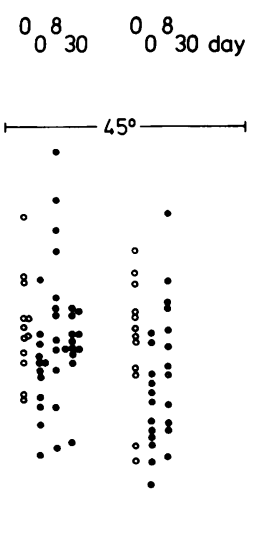

Fig. 2 Number of turns $/ 5 \mathrm{~s}$ and amplitude between turns at 10 per cent of maximum force. ○ normal quadriceps muscle; - disused muscle. Each point represents recordings from a given site in the muscle. Above the columns: day(s) after the patient could bend his knee to $90^{\circ}$ or to $45^{\circ}$. Below the columns: maximum force of the disused muscle as a percentage of the maximum force of the contralateral muscle.

the mean amplitude were as in the normal muscle (Figs. 2 and 3). The maximum force of the disused muscle had increased further, the diminution being 0 to $20 \%$ of $\mathrm{P}_{0}$ of the contralateral quadriceps muscle (Fig. 1).

ELECTRICAL ACTIVITY AT A FIXED FORCE OF 5 KG The force of $5 \mathrm{~kg}$ corresponded to 15 to $55 \%$ of $\mathbf{P}_{0}$ of the disused muscle. On days 0,8 , and 30 , the number of turns/5s and the mean amplitude between turns were the same in the disused and in the normal muscle with one exception. One patient had a $35 \%$ increase in the number of turns on day 0 , whereas the mean amplitude between turns was as in the contralateral muscle. 
30 PER CENT OF MAXIMUM FORCE

TURNS PER $5 \mathrm{~s}$
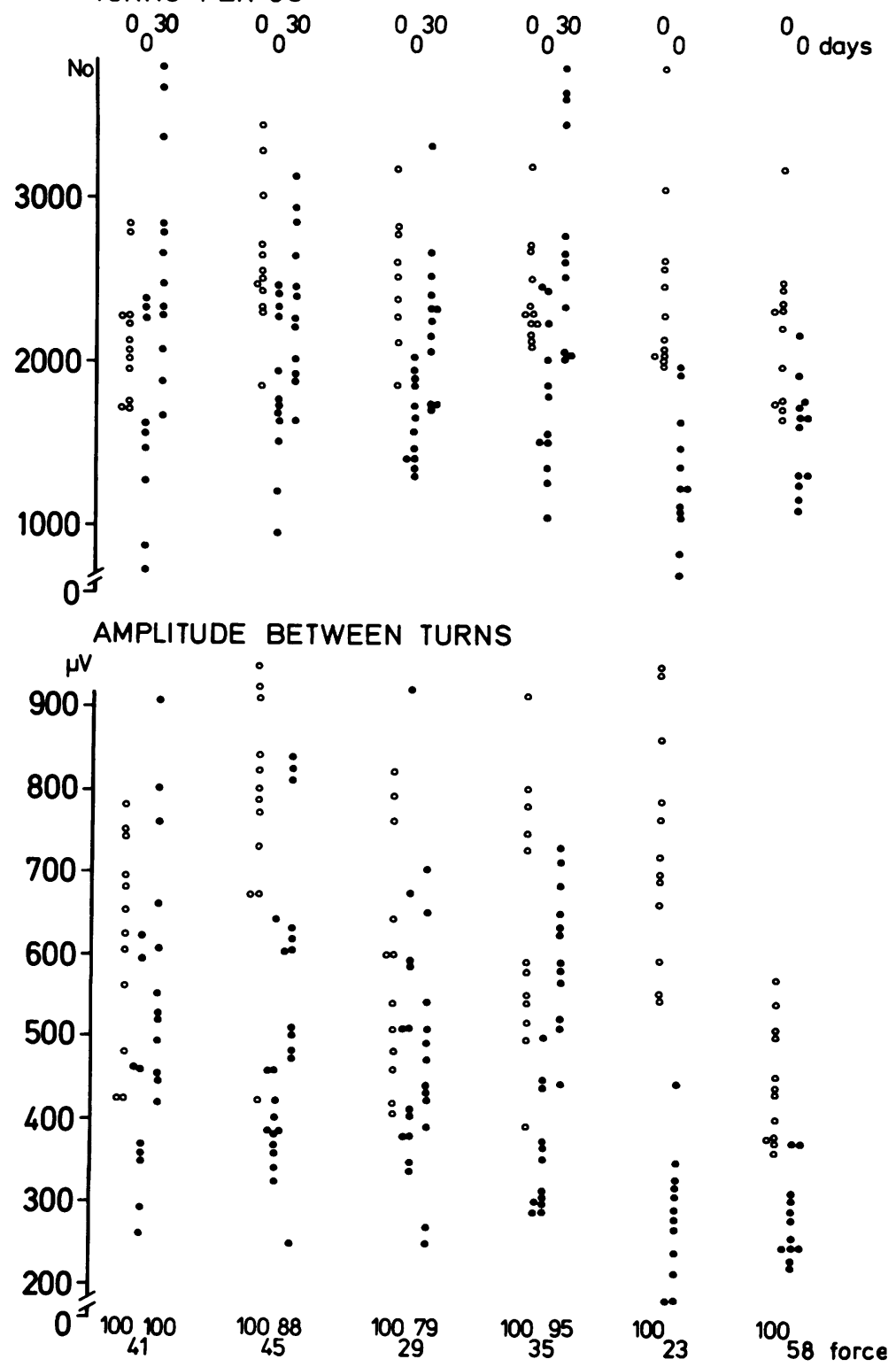

The number of turns and the mean amplitude in the normal muscle were re-examined on day 30 and did not differ from findings on day 0 .

ELECTROMYOGRAPHY DURING WEAK EFFORT AND PATTERN OF RECRUITMENT DURING FULL EFFORT On day 0 the mean duration and the mean amplitude of motor unit potentials were the same in the disused and in the normal medial vastus muscle, as
Fig. 3 Number of turns/5s and amplitude between turns at $30 \%$ of maximum force (notes and symbols as for Fig. 2). was the incidence of polyphasic potentials. The pattern of recruitment during full effort and the amplitude of the envelope curve were slightly diminished in five of eight patients.

\section{Discussion}

A prerequisite for the validity of our observations is the assumption that during full effort all motor 


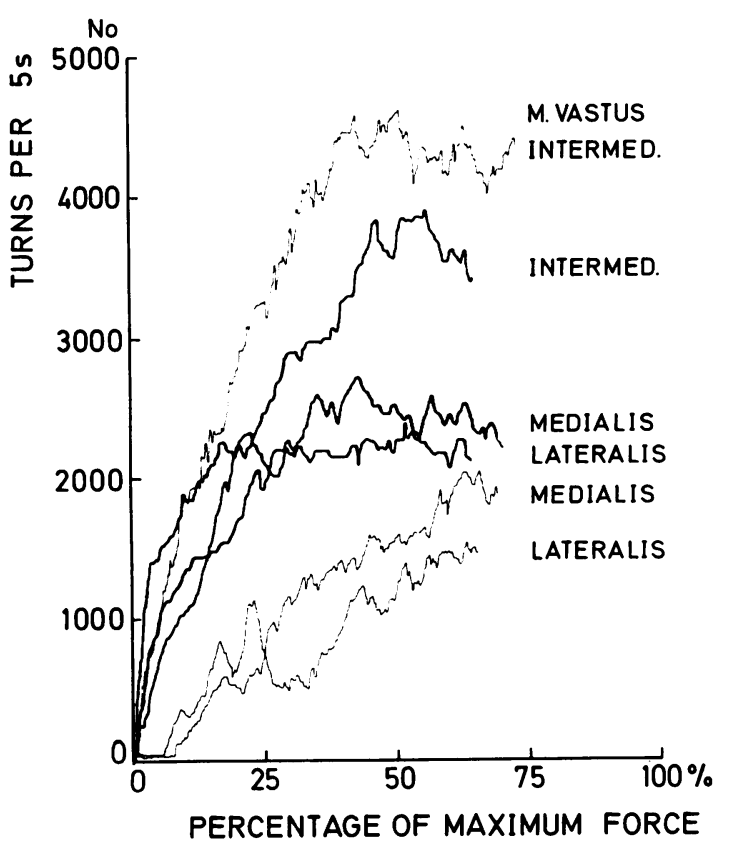

Fig. 4 Number of turns/5s as a function of force of the disused muscle recorded in intervals of $100 \mathrm{~ms}$ in patient 1. The force increased linearly within 10 s. Thin lines: disused quadriceps muscle, thick lines: contralateral quadriceps muscle.

units that could be activated were activated. The patients were soccer and handball players and easy to motivate to exert full effort. The maximum force $\left(\mathbf{P}_{0}\right)$ was determined before the electrodes were inserted and after they had been removed. The exertion of full force was not hampered by pain.

The main finding of this study was the transient decrease in the number of turns, present after immobilisation, at a relative force of 10 to $75 \%$ of $P_{0}$ of the disused muscle. This indicates that the number of motor units activated at a given relative force was diminished. The reduced number of motor units explains the disproportionately large diminution in maximum force on day 0 and the reduced pattern of recruitment during full effort in five patients. The decline in force could not be a result of the diminished cross-sectional area of the muscle fibres associated with disuse, because on day 8 the force had largely recovered and the number of turns/5s and the amplitude between turns were normal, though the muscles had not been trained.

That the diminution in cross-sectional area of the disused muscle could not fully account for the diminution in force confirms findings in cats and rats. The force decreased disproportionately more than the wet weight of the disused muscle (Eccles, 1941; Fischbach and Robbins, 1969; Davis and Montgomery, 1977). The slight to moderate diminution in force, present on day 8 , disappeared gradually, probably because of a gradual increase in cross-sectional area of the muscle fibres. One might have expected that the reduced crosssectional area of the muscle fibres, assumed to explain the diminished force from day 8 to day 30 , would be reflected in a compensatory increase in the number of turns when the muscle exerted a fixed force of $5 \mathrm{~kg}$. That the number of turns and the mean amplitude of the EMG recording remaining unchanged indicated that they were insensitive indicators of a change in force secondary to changes in the cross-sectional area of the muscle fibres. This was corroborated by findings in normal subjects in whom different strengths were probably the result of different cross-sectional areas of the muscle fibres (Fuglsang-Frederiksen and Månsson, 1975). In the quadriceps muscle EMG the different strengths were reflected in the number of turns to an even lesser degree than in the brachial biceps muscle (Fig. 5). At a fixed load of $5 \mathrm{~kg}$ the number of turns was $25 \%$ higher in the quadriceps muscle of normal subjects who exerted a maximum force of $30 \mathrm{~kg}$ than in subjects who exerted $80 \mathrm{~kg}$ - that is, an increase of $25 \%$ in turns corresponded to a $63 \%$ lower force. In the patients the diminution in force on day 8 was 15 to $30 \%$. This would cause an increase in the number of turns of at most $10 \%$, which is within the error of the method even if two muscles of the same individual are compared.

The number of turns, recorded at a fraction of the force adjusted in proportion to $\mathrm{P}_{0}$, compared with the number of turns at a constant force distinguished whether a decrease in strength was due to loss of motor units or to a diminution in crosssectional area of the muscle fibres. In patients with motor neurone disease the number of turns at a constant force was normal (Hayward and Willison, 1977) whereas the number of turns was decreased at a force adiusted to $\mathbf{P}_{0}$ (Fuglsang-Frederiksen et al., 1977). The loss of motor units evident at a given relative force also appeared as a decrease in the mean amplitude, probably because there were fewer potentials to summate. Hayward (1977) believed summation to be of minor importance; the decrease in the number of turns and the increase in amplitude seen in normal subjects above a force of $50 \%$ of $\mathbf{P}_{0}$ (Fuglsang-Frederiksen and Månsson, 1975) was, however, best accounted for by a change in summation-that is, cancellation and addition of component potentials. 


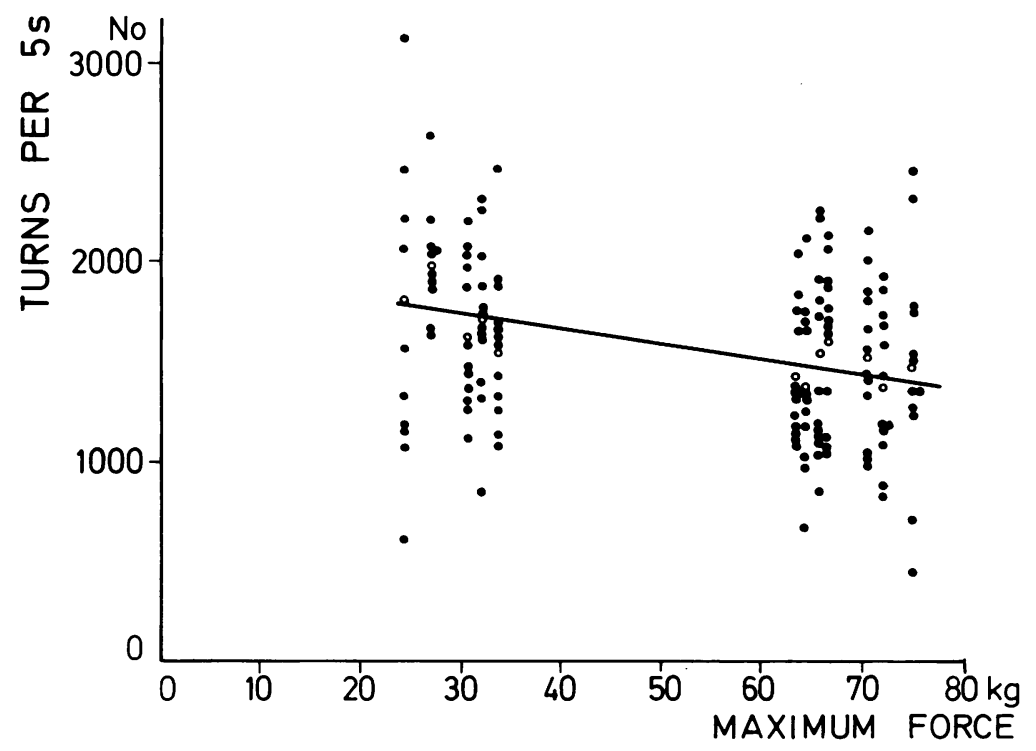

Fig. 5 Number of turns $/ 5 \mathrm{~s}$ at a force of $5 \mathrm{~kg}$ in the quadriceps muscle as a function of the maximum force in the quadriceps of 12 subjects of different strengths. (Number of turns $/ 5 s=1960-7.3 \times P_{0}$ ). The regression line was determined with a significance of $P \leqslant 0.01$. The open circles give the average of mesaurements in 12 sites (solid circles).

The diminution in the number of motor units on day 0 is a sign of functional plasticity in the motor system. Within the first week after day 0 the number of motor units activated was no longer different from that activated in the normal leg at the same relative force. Possibly the more intense flow of afferent impulses (Houk and Henneman, 1967) associated with the recovery of function of the knee joint on day 8, can explain why more motor units were activated on day 8 than on day 0 .

We are indebted to Professor F. Buchthal for his unfailing help. We wish to thank Professor E. Snorrason for his interest in the study, and Dr J. Halkjær-Christensen and Dr P. Ingemann-Hansen (Department of Physical Medicine of the Rigshospital) for selecting the patients and referring them for electrophysiological studies. The work was supported by a grant from the Muscular Dystrophy Associations of America, New York, to Professor Buchthal.

\section{References}

Adams, R. D. (1975). Diseases of Muscle, a Study in Pathology. Third edition, pp. 588. Harper and Row: Hagerstown, Maryland.

Buchthal, F. (1957). An Introduction to Electromyography, pp. 43. Gyldendal: Copenhagen.

Davis, C. J. F., and Montgomery, A. (1977). The effect of prolonged inactivity upon contraction characteristics of fast and slow mammalian twitch muscle. Journal of Physiology, 270, 581-594.
Eccles, J. C. (1941). Disuse atrophy of skeletal muscle. Medical Journal of Australia, 2, 160-173.

Fischbach, G. D., and Robbins, N. (1969). Changes in contractile properties of disused soleus muscle. Journal of Physiology, 201, 305-320.

Fitch, P. (1967). An analyser for use in human electromyography. Electronic Engineering, 39, 240-243.

Fuglsang-Frederiksen, A., and Månsson, A. (1975). Analysis of electrical activity of normal muscle in man at different degrees of voluntary effort. Journal of Neurology, Neurosurgery, and Psychiatry, 38, 683-694.

Fuglsang-Frederiksen, A., Scheel, U., and Buchthal, F. (1977). Diagnostic yield of the analysis of the pattern of electrical activity of muscle and of individual motor unit potentials in neurogenic involvement. Journal of Neurology, Neurosurgery, and Psychiatry, 40, 544-554.

Hayward, M. (1977). Automatic analysis of the electromyogram in healthy subjects of different ages. Journal of the Neurological Sciences, 33, 397-413.

Hayward, M., and Willison, R. G. (1977). Automatic analysis of the electromyogram in patients with chronic partial denervation. Journal of the Neurological Sciences, 33, 415-423.

Houk, J., and Henneman, E. (1967). Response of Golgi tendon organs to active contractions of the soleus muscle in cat. Journal of Neurophysiology, 30, 466-481.

Thage, O., (1974). Quadriceps Weakness and Wasting, pp. 132. Association of Danish Physicians: Copenhagen, Århus, Odense.

Willison, R. G. (1964). Analysis of electrical activity in healthy and dystrophic muscle in man. Journal of Neurology, Neurosurgery, and Psychiatry, 27, 386394. 